\title{
Milliliter per Centimeter
}

National Cancer Institute

\section{Source}

National Cancer Institute. Milliliter per Centimeter. NCI Thesaurus. Code C105503.

A unit of measure equal to the number of milliiters per unit of length equal to one centimeter. 